Gut and Liver, Vol. 11, No. 3, May 2017, pp. 417-425

\title{
Expression of Hepatocyte Hepatitis B Core Antigen and Hepatitis B Surface Antigen as a Marker in the Management of Chronic Hepatitis B Patients
}

Sun Young Yim ${ }^{1}$, Tae Hyung $\mathrm{Kim}^{1}$, Suh Sang Jun ${ }^{1}$, Eun Sun $\mathrm{Kim}^{1}$, Bora Keum ${ }^{1}$, Yeon Seok Seo ${ }^{1}$, Hyung Joon Yim ${ }^{1}$, Yoon Tae Jeen ${ }^{1}$, Hoon Jai Chun ${ }^{1}$, Hong Sik Lee ${ }^{1}$, Soon Ho Um ${ }^{1}$, Chang Duck Kim ${ }^{1}$, Nam Hee Won ${ }^{2}$, and Ho Sang Ryu ${ }^{1}$

Departments of ${ }^{1}$ Internal Medicine and ${ }^{2}$ Pathology, Korea University College of Medicine, Seoul, Korea

Background/Aims: We aimed to clarify the association of hepatitis B surface antigen (HBsAg)/hepatitis B core antigen (HBcAg) with the disease status and treatment response in patients with chronic hepatitis B (CHB). Methods: We investigated 171 biopsy-proven entecavir-treated CHB patients (109 hepatitis B e antigen [HBeAg]-positive, 62 HBeAg-negative). HBcAg expression was positive when $\geq 10 \%$ of hepatocytes stained, and classified into nuclear, mixed, and cytoplasmic patterns. HBsAg expressions were intracytoplasmic (diffuse, globular, and submembranous) and membranous. The histologic activity index (HAl) and fibrosis stage followed Ishak system. Results: In HBeAg-positive patients, older age, increased HAl score, advanced fibrosis, and reduced viral load were observed when HBcAg expression shifted from nucleus to cytoplasm in HBcAg-positive patients, and HBsAg expression from non-submembranous to submembranous in HBcAg-negative patients (all, $p<0.05$ ). In HBeAg-negative patients, only intracytoplasmic HBsAg expression patterns had clinical relevance with decreased ALT levels and viremia. In HBeAg-positive patients without favorable predictors of virologic response, negative $\mathrm{HBcAg}$ and membranous HBsAg expression predicted greater virologic response (both, $p<0.05$ ). The probability of HBeAg seroclearance was higher in patients with increased $\mathrm{HAl}$ or lacking HBcAg expression (both, $p<0.05$ ). Higher serum HBsAg levels and hepatocyte $\mathrm{HBCAg}$ positivity were associated with reduced serum HBsAg during first and post-first year treatment, respectively (both, $\mathrm{p}<0.05)$. Conclusions: Hepatocyte $\mathrm{HBcAg} / \mathrm{HBsAg}$ expression is a good marker for disease status and predicting treatment response. (Gut Liver 2017;11:417-425)

Key Words: Hepatitis B, chronic; Hepatitis B core antigens; Hepatitis B surface antigens; Histologic activity index

\section{INTRODUCTION}

Chronic hepatitis B (CHB) may occasionally progress to liver cirrhosis and hepatocellular carcinoma (HCC). ${ }^{1}$ Antiviral treatment is usually indicated for patients with CHB who have hepatitis B virus (HBV) DNA levels above 2,000 IU/mL, serum alanine aminotransferase (ALT) levels above the upper limit of normal, and histologically moderate-to-severe active necroinflammation and/or at least moderate fibrosis. ${ }^{2}$ Several factors are associated with the main endpoints of antiviral treatment. High serum ALT level, low viremia, and high activity scores on liver biopsy are related to hepatitis B e antigen (HBeAg) seroconversion; ${ }^{2}$ the dynamics of serum hepatitis B surface antigen (HBsAg) levels during treatment appears predictive of not only sustained off-treatment virologic response but also HBsAg loss in HBeAg-negative patients, which is the ultimate goal of antiviral treatment. ${ }^{3-5}$ Although the abovementioned factors are associated with good treatment response, some patients without favorable factors still show adequate response to antiviral treatment, while those with favorable factors do not achieve HBsAg seroclearance. These imply that other conditions, such as viral or host factors, can also be important predictors of the outcomes of antiviral treatment.

The intrahepatic expressions of hepatitis B core antigen (HBcAg) and HBsAg are related to the histologic activity of hepatitis, viral replication, and host immune response, and variable expression patterns are observed during the natural course of CHB. The intrahepatic expression of HBcAg is reportedly related to the presence of serum HBeAg and HBV replication, and its expression patterns have also been correlated with the degree of hepatic inflammation. ${ }^{6-9}$ Furthermore, the presence of hepatocytes with HBsAg membranous staining was positively correlated with serum HBV DNA levels, suggesting its role as

Correspondence to: Soon Ho Um

Department of Internal Medicine, Korea University College of Medicine, 73 Inchon-ro, Seongbuk-gu, Seoul 02841, Korea

Tel: +82-2-920-6555, Fax: +82-2-953-1943, E-mail: umsh@korea.ac.kr

Received on March 18, 2016. Revised on June 28, 2016. Accepted on September 26, 2016. Published online February 17, 2017 pISSN 1976-2283 eISSN 2005-1212 https://doi.org/10.5009/gnl16148

(a) This is an Open Access article distributed under the terms of the Creative Commons Attribution Non-Commercial License (http://creativecommons.org/licenses/by-nc/4.0) which permits unrestricted non-commercial use, distribution, and reproduction in any medium, provided the original work is properly cited. 
a marker of active viral replication. ${ }^{10,11}$ These findings suggest that the expression of intrahepatic $\mathrm{HBsAg}$ or $\mathrm{HBcAg}$ might be utilized to predict the response to antiviral treatment.

A few studies have suggested the potential of using intrahepatic $\mathrm{HBcAg}$ as a predictor of antiviral treatment response. ${ }^{12-14}$ However, these studies included a small number of patients, and intrahepatic HBsAg as a marker of treatment response was not analyzed. Furthermore, information regarding the association between intrahepatic $\mathrm{HBcAg} / \mathrm{HBsAg}$ and the decline in serum HBsAg levels during treatment is lacking. In the present study, we aimed to clarify the role of intrahepatic expression patterns of HBsAg and HBcAg in assessing the disease status, and predicting virologic and serologic response to a high potency antiviral drug, entecavir.

\section{MATERIALS AND METHODS}

\section{Patients}

A retrospective cohort of 171 patients with $\mathrm{CHB}$ and $\mathrm{HBV}$ related liver cirrhosis, who underwent liver biopsies from January 2007 to December 2013, was enrolled. All patients received entecavir $(0.5 \mathrm{mg})$ as a primary treatment within 3 months after liver biopsy, and were monitored at intervals of 3 months. The inclusion criteria were the presence of positive serum HBsAg for at least 6 months, and absence of infection with the hepatitis C, hepatitis D, and human immunodeficiency viruses. Patients with other causes of chronic liver injury, such as autoimmune hepatitis, alcoholic hepatitis, Wilson's disease, and primary biliary cirrhosis, were excluded. Since almost all Korean patients with $\mathrm{CHB}$ are reported to be infected with genotype $\mathrm{C}$ virus, the enrolled patients were assumed to be genotype C HBV carriers. ${ }^{15-17}$

This study was approved by the Institutional Review Board of Korea University Hospital and was conducted in accordance with the Declaration of Helsinki. Waiver of consent was obtained.

\section{Efficacy analysis}

Virologic response (VR) was defined as an undetectable serum HBV DNA level $(<20 \mathrm{IU} / \mathrm{mL})$ by real-time polymerase chain reaction (PCR). Serological response was defined as $\mathrm{HBeAg}$ seroclearance and reduction in serum HBsAg level. Significant $\mathrm{HBsAg}$ reduction was defined as a decrease in serum HBsAg level $>0.5 \log _{10} \mathrm{IU} / \mathrm{mL}$ during follow-up after initiating antiviral treatment. ${ }^{18}$

\section{Laboratory analysis}

Serum HBsAg, antibody to HBsAg (anti-HBs), HBeAg, and antibody to HBeAg were analyzed by radioimmunoassay (Abbott Laboratories, Abbott Park, IL, USA). Serum HBV DNA levels were quantified by real-time PCR assay (COBAS AmpliPrep/COBAS TaqMan; Roche Diagnostics, Indianapolis, IN, USA), with a detection range of 20 to $1.7 \times 10^{8} \mathrm{IU} / \mathrm{mL}$. Serum $\mathrm{HBsAg}$ was quantified with ARCHITECT HBsAg assay (Abbott Laboratories) with a detection range from 0.05 to $250 \mathrm{IU} / \mathrm{mL}$. Samples with serum $\mathrm{HBsAg}$ levels of $>250 \mathrm{IU} / \mathrm{mL}$ were diluted in order to bring the reading into the calibration curve range.

\section{Histologic analysis}

Immunohistochemical staining for $\mathrm{HBsAg}$ and $\mathrm{HBCAg}$ within the hepatocytes was done using commercially available antiHBs and anti-HBc (1:100; Cell Marque, Rocklin, CA, USA) (Supplementary Appendix 1). Hepatocyte HBcAg expression was classified according to nuclear, cytoplasmic, and mixed types (Supplementary Fig. 1). The expression patterns of HBsAg were categorized according to intracytoplasmic expression (diffuse, globular, submembranous) and presence of membranous expression (Supplementary Fig. 2). The degree of expression was scored from 0 to 4 , with values corresponding to $0 \%-1 \%$, $2 \%-10 \%, 11 \%-25 \%, 26 \%-50 \%$, and $>50 \%$ of hepatocytes examined. $^{19}$

Histologic activity index (HAI) and fibrosis stages were assessed using the Ishak system. ${ }^{20} \mathrm{HAI}$ grading consists of the sum of necroinflammatory scores, including periportal or periseptal interface hepatitis (piecemeal necrosis), confluent necrosis, focal (spotty) lytic necrosis, and portal inflammation; each was assigned a score from 0 to $4-6$, yielding a maximal HAI grade of 18. Fibrosis staging ranged from 0 to 6 .

\section{Statistical analysis}

Statistical analysis was performed using the SPSS version 20.0 (IBM Corp., Armonk, NY, USA). Continuous variables with parametric distribution were analyzed using Student t-test and analysis of variance, with the Mann-Whitney U-test and Kruskal-Wallis test for nonparametric distribution. Categorical variables were compared using the chi-square test. Factors associated with VR and serologic responses were assessed with Cox regression analysis and binary logistic regression. Multivariate analysis was performed after including the variables of the univariate analysis with $\mathrm{p}$-values $<0.1$. The Kaplan-Meier method (using the log rank test for comparisons) was used to calculate the cumulative incidence of VR, HBeAg seroclearance, and significant HBsAg decline. The $\mathrm{p}$-values of $<0.05$ were considered statistically significant.

\section{RESULTS}

\section{Baseline clinicopathological characteristics according to $\mathrm{HBeAg}$ serostatus}

At baseline, the mean age of all patients $(n=171)$ was $46 \pm 11$ years, with male predominance (62.6\%). Of these, 109 patients (63.7\%) were HBeAg-positive, while 62 (36.3\%) were HBeAgnegative. HBeAg-positive patients were younger, with increased viremia compared to $\mathrm{HBeAg}$-negative patients (both $\mathrm{p}<0.05$ ) (Table 1). 
In 171 biopsied specimens, hepatocyte HBcAg expression was detected in 95 (55.6\%), while membranous and intracytoplasmic HBsAg expression in 71 (41.5\%) and 167 patients (97.7\%), respectively. Hepatocyte $\mathrm{HBcAg}$ was expressed in a remarkably higher proportion of patients in the HBeAg-positive, compared to the HBeAg-negative group ( $73.4 \%$ vs $24.2 \%$, p<0.001) (Table 1 ), and their median degree of expression was also significantly higher (score, 2 vs $0 ; \mathrm{p}<0.001$ ). Hepatocyte HBsAg expression also differed between $\mathrm{HBeAg}$-positive and -negative groups. There was significantly higher diffuse intracytoplasmic $\mathrm{HBsAg}$ expression (57.8\% vs 37.1\%, p=0.014) in HBeAg-positive compared to HBeAg-negative patients.

\section{Clinical features in relation to hepatocyte $\mathrm{HBcAg}$ and HBsAg expression at baseline}

Through detailed analysis of clinical and histologic findings according to $\mathrm{HBeAg}$ serostatus (Supplementary Tables 1 and 2), the degree of $\mathrm{HBcAg}$ expression ( $\geq 10 \%$ vs $<10 \%$ of hepatocytes observed) was independently correlated with high viremia (odds ratio [OR], 3.372; 95\% confidence interval [CI], 1.072 to 10.607; $\mathrm{p}=0.038$ ) and advanced fibrosis (OR, 0.215; 95\% CI, 0.069 to 0.673 ; $\mathrm{p}=0.008$ ) in $\mathrm{HBeAg}$ positive patients; for those with positive $\mathrm{HBcAg}$ expression (seen in $\geq 10 \%$ of hepatocytes), the staining pattern (HBcAg nuclear/mixed vs cytoplasmic) was also correlated with viremia (OR, 4.405; 95\% CI, 1.14 to 16.949 ; $\mathrm{p}=0.032$ ). Furthermore, intracytoplasmic HBsAg expression pattern (submembranous vs non-submembranous) was independently associated with higher HAI (score $\geq 9$ ) (OR, 4.356; 95\% CI, 1.22 to $15.55 ; \mathrm{p}=0.023$ ) and advanced fibrosis (OR, 6.245; 95\% CI, 1.482 to 26.314; $\mathrm{p}=0.013$ ) in the HBeAg-positive group. However, in $\mathrm{HBeAg}$-negative group, intracytoplasmic HBsAg expression pattern (submembranous vs non-submembranous)

Table 1. Baseline Clinical Characteristics According to Baseline HBeAg Seropositivity

\begin{tabular}{|c|c|c|c|c|}
\hline Variable & Total & HBeAg positive & HBeAg negative & p-value \\
\hline No. of patients & 171 & 109 & 62 & - \\
\hline Age, yr & $46 \pm 11$ & $44 \pm 12$ & $48 \pm 10$ & 0.016 \\
\hline Male sex & $107(62.6)$ & $66(60.6)$ & $41(66.1)$ & 0.469 \\
\hline Liver cirrhosis & $36(21.1)$ & $22(20.2)$ & $14(22.6)$ & 0.712 \\
\hline HBV DNA, $\log _{10} I U / m L$ & $7.14(3.34-9.24)$ & $7.86(3.96-9.24)$ & $6.12(3.34-8.23)$ & $<0.001$ \\
\hline HBsAg, $\log _{10} \mathrm{IU} / \mathrm{mL}$ & $3.57(1.74-4.79)$ & $3.63(1.74-4.79)$ & $3.54(1.88-4.29)$ & 0.212 \\
\hline $\mathrm{ALT} \geq 200 \mathrm{IU} / \mathrm{L}$ & $45(26.3)$ & $34(31.2)$ & $11(17.7)$ & 0.055 \\
\hline HAI score $\geq 9$ & $60(35.1)$ & $42(38.5)$ & $18(29)$ & 0.211 \\
\hline Fibrosis stage $\geq 4$ & $72(42.1)$ & $49(45)$ & $23(37.1)$ & 0.317 \\
\hline \multicolumn{5}{|l|}{ HBcAg expression } \\
\hline Degree of expression, score & $1(0-4)$ & $2(0-4)$ & $0(0-3)$ & $<0.001$ \\
\hline Expression pattern & & & & $<0.001$ \\
\hline Nuclear & $25(14.6)$ & $21(19.3)$ & $4(6.5)$ & \\
\hline Mixed & $18(10.6)$ & $16(14.7)$ & $2(3.2)$ & \\
\hline Cytoplasmic & $52(30.4)$ & $43(39.4)$ & $9(14.5)$ & \\
\hline Absent & $76(44.4)$ & $29(26.6)$ & 47 (75.8) & \\
\hline \multicolumn{5}{|l|}{ HBsAg expression } \\
\hline Membranous expression & & & & 0.126 \\
\hline Present & $71(41.5)$ & $50(45.9)$ & $21(33.9)$ & \\
\hline Absent & $100(58.5)$ & $59(54.1)$ & $41(66.1)$ & \\
\hline Intracytoplasmic expression & & & & 0.014 \\
\hline Diffuse & $86(50.3)$ & $63(57.8)$ & $23(37.1)$ & \\
\hline Globular & $34(19.9)$ & $19(17.4)$ & $15(24.2)$ & \\
\hline Submembranous & $47(27.5)$ & $23(21.1)$ & $24(38.7)$ & \\
\hline Absent & $4(2.3)$ & $4(3.7)$ & 0 & \\
\hline
\end{tabular}

Data are presented as mean $\pm \mathrm{SD}$, number (\%), or median (range).

The p-values were obtained using the chi-square test for categorical variables and Student t-test and Mann-Whitney U-test for continuous variables. The degree of hepatocytes staining was scored from 0 to 4 , with percentage values corresponding to $0 \%, 1 \%-10 \%, 11 \%-25 \%, 26 \%-50 \%$, $>50 \%$ of hepatocytes examined, respectively. HAI grade and fibrosis stages were assessed using the Ishak system. The HAI yielded a maximal score of 18 , whereas the fibrosis stage ranged from 0 to 6 .

$\mathrm{HBeAg}$, hepatitis B e antigen; HBV, hepatitis B virus; HBsAg, hepatitis B surface antigen; ALT, alanine aminotransferase; HAI, histologic activity index; HBcAg, hepatitis B core antigen. 
was independently associated with high viremia only (OR, 0.26; 95\% CI, 0.079 to $0.855 ; \mathrm{p}=0.027$ ).

Based on the above results, we divided HBeAg positive patients into four subgroups, according to hepatocyte $\mathrm{HBcAg}$ and HBsAg expression. Those who exhibited positive HBcAg expression were grouped by the expression pattern into nuclear/mixed (group 1) or cytoplasmic (group 2) types. Those who demonstrated negative $\mathrm{HBcAg}$ expression (seen in $<10 \%$ of hepatocytes or no expression of $\mathrm{HBcAg}$ ) were grouped according to intracytoplasmic HBsAg expression pattern into non-submembranous (group 3) or submembranous (group 4) types. By this grouping, age, the proportion of subjects with liver cirrhosis, high HAI score, and advanced fibrosis increased, while serum HBV DNA and HBsAg levels decreased, when the hepatocyte $\mathrm{HBcAg} / \mathrm{HBsAg}$ expression patterns changed from group 1 to 4 (all, $\mathrm{p}<0.05$ ) (Table 2). When further comparisons were made between groups, there was a remarkable increase in age, incidence of high HAI score $(\geq 9)$, and advanced fibrosis stage $(\geq 4)$, but a decrease in serum HBsAg levels in group 2, compared to group 1 ; in contrast, serum HBV DNA levels significantly decreased in group 3, compared to group 2; there was a further decrease in serum HBsAg levels, with an increase in the incidence of high HAI score and fibrosis stage in group 4, compared to group 3 (all, $\mathrm{p}<0.05)$. For HBeAg-negative patients, there was a significant decrease in the proportion of subjects with high ALT levels, and a tendency toward lower median serum HBV DNA levels, when HBsAg intracytoplasmic expression changed from a non-submembranous to submembranous pattern $(\mathrm{p}=0.004$ and $\mathrm{p}=0.071$, respectively).

\section{Factors associated with VR}

Patients were treated for a median duration of 48 months (range, 6 to 96 months). VR was achieved in 95 of $109 \mathrm{HBeAg-}$ positive patients (87.2\%), and in all of $62 \mathrm{HBeAg}$-negative patients (100\%), with a median time to VR of 12 and 6 months, respectively. Independent factors associated with VR are shown in Table 3.

In $\mathrm{HBeAg}$-positive patients with unfavorable predictors of $\mathrm{VR}$, that is, lower ALT level ( $<200 \mathrm{IU} / \mathrm{L})$ and early fibrosis (stage $<4)$, cumulative incidence of VR was significantly higher in those with negative $\mathrm{HBcAg}$ expression (vs positive expression) at 1- and 2-year follow-up (67\% vs $27 \%$ and $84 \%$ vs 54\%, respectively; log-rank, $\mathrm{p}=0.006$ ).

\section{Factors associated with the seroclearance of $\mathrm{HBeAg}$}

Of $109 \mathrm{HBeAg}$-positive patients, 52 (47.7\%) exhibited HBeAg seroclearance, with a median time of 20 months (range, 2 to 73 months). Higher HAI (score $\geq 9$ ) and negative hepatocyte HBcAg expression were the independent factors associated with $\mathrm{HBeAg}$ seroclearance $(p<0.001$ and $p=0.049$, respectively) (Table 3).

Since the independent factors associated with HBeAg seroclearance were higher HAI and negative HBcAg expression,

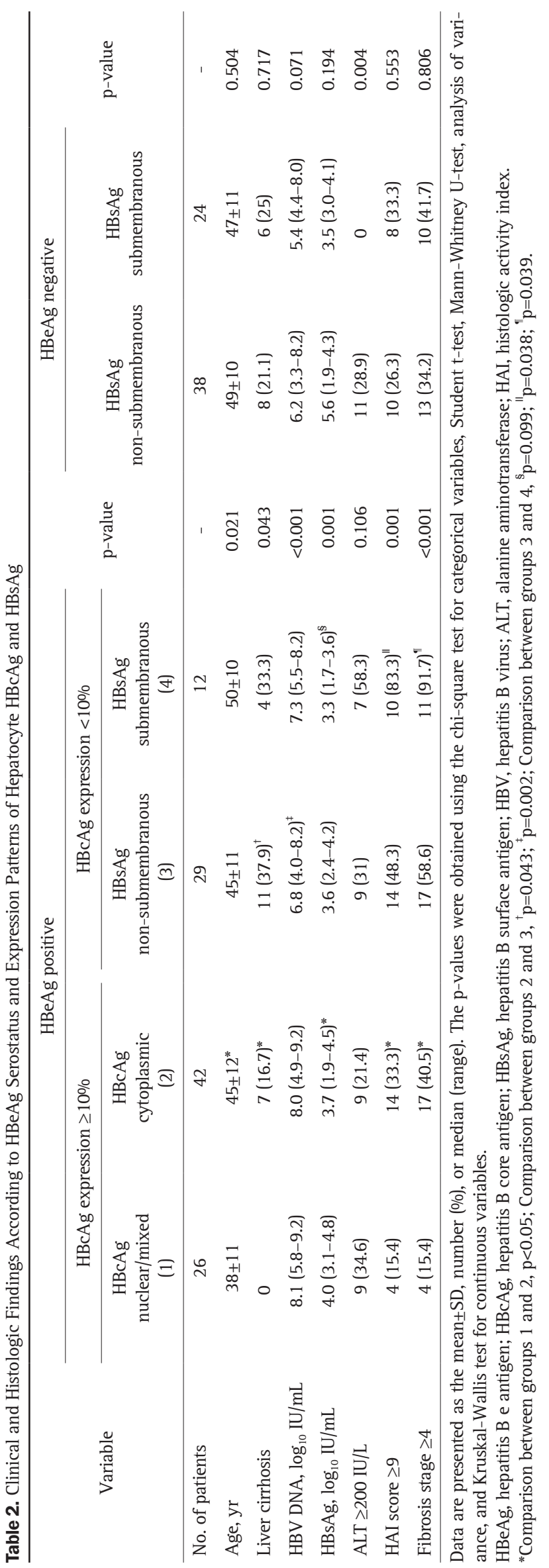




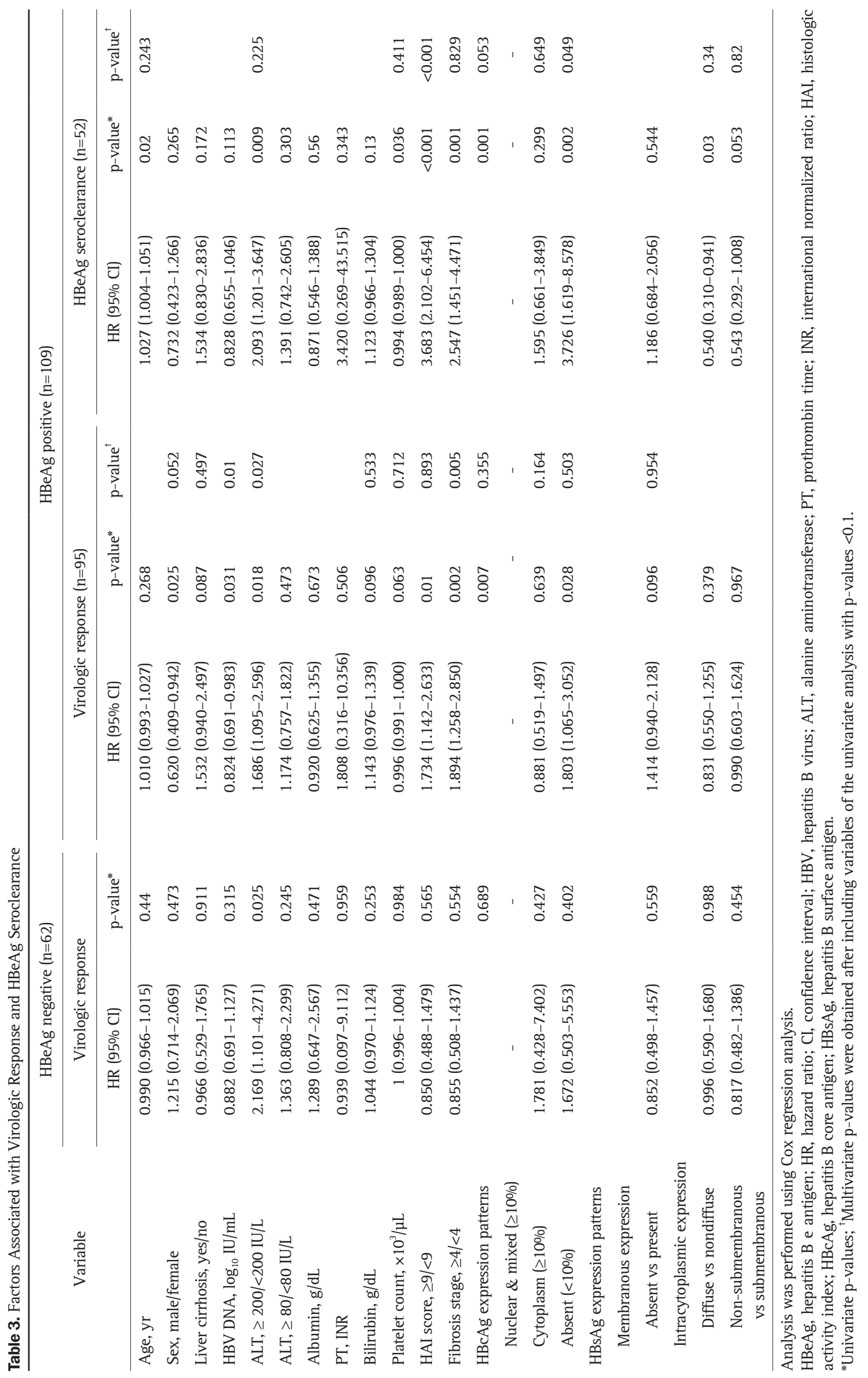



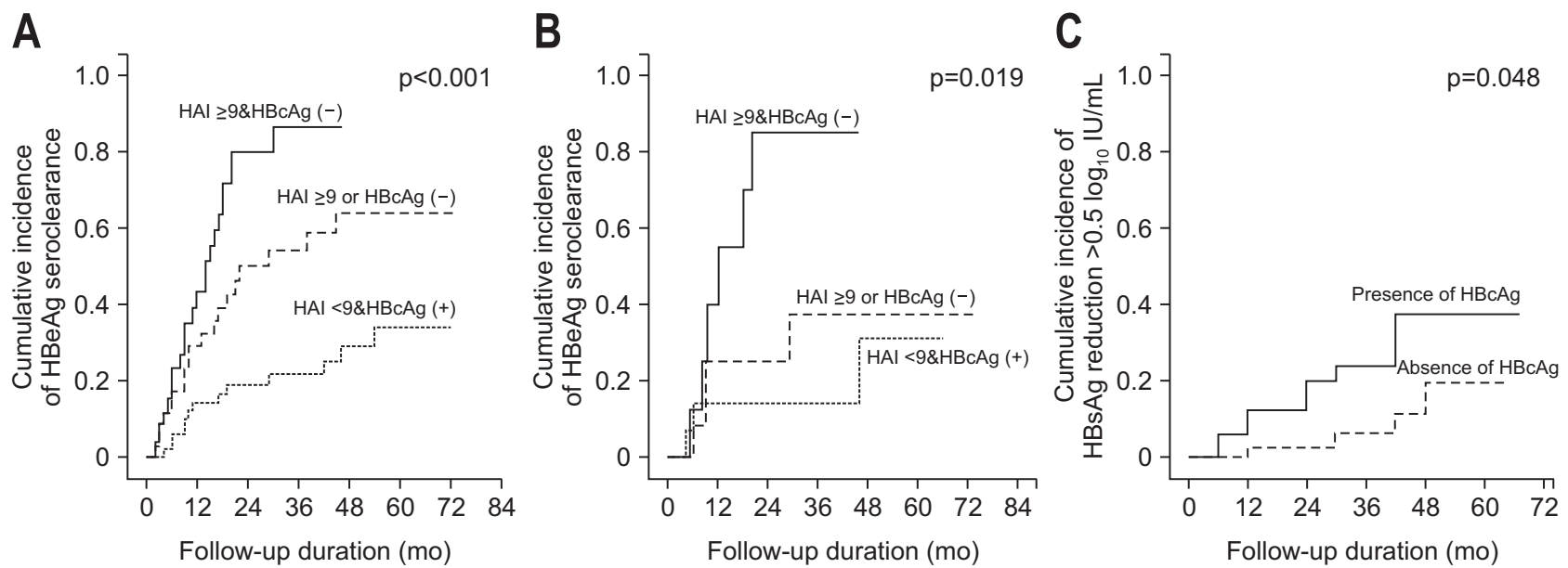

Fig. 1. Kaplan-Meier curve analysis in hepatitis B e antigen (HBeAg)-positive patients. (A) Cumulative incidence of HBeAg seroclearance (KaplanMeier plot) according to the histologic activity index (HAI; score $\geq 9$ ) and presence of hepatocyte hepatitis B core antigen (HBcAg) expression. (B) Cumulative incidence of HBeAg seroclearance according to the HAI (score $\geq 9$ ) and presence of hepatocyte HBcAg expression in patients with low alanine aminotransferase (ALT; <80 IU/L) levels. (C) Cumulative incidence of significant hepatitis B surface antigen (HBsAg) reduction according to the presence of hepatocyte $\mathrm{HBcAg}$ expression.

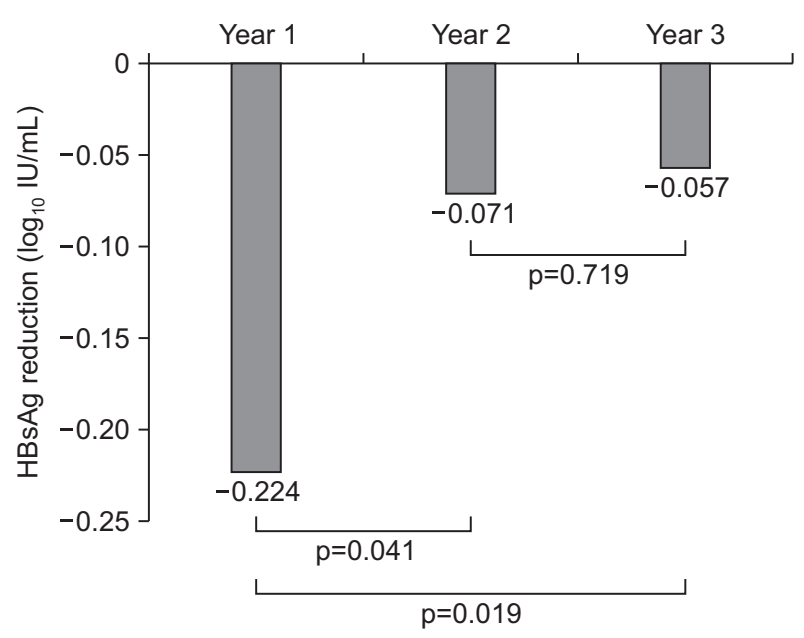

Fig. 2. Yearly mean hepatitis B surface antigen (HBsAg) reduction among patients followed up for 3 years.

patients were divided into three subgroups according to these variables. Patients with both higher HAI (score $\geq 9$ ) and negative HBcAg expression ( $n=24)$ had the highest cumulative incidence of HBeAg seroclearance, followed by those fulfilling either higher HAI or negative HBcAg expression $(n=35)$, and was lowest in those with both lower HAI and positive HBcAg expression ( $n=50)$ $(p<0.001)$ (Fig. 1A). The incidence of HBeAg seroclearance was still the highest in patients with increased HAI (score $\geq 9$ ) and negative $\mathrm{HBcAg}$ expression even when patients with lower ALT $(<80 \mathrm{IU} / \mathrm{L})$ levels were analyzed ( $\mathrm{p}=0.019)$ (Fig. 1B).

\section{Factors associated with significant HBsAg reduction}

Among 38 patients with 3 years of follow-up, mean HB$\mathrm{sAg}$ reduction was significantly greater during the first year of treatment $\left(-0.22 \pm 0.41 \log _{10} \mathrm{IU} / \mathrm{mL}\right)$, when compared to the second year, $\left(-0.071 \pm 0.19 \log _{10} I U / m L, p=0.041\right)$, and third year $\left(0.057 \pm 0.12 \log _{10} \mathrm{IU} / \mathrm{mL}, \mathrm{p}=0.019\right)$, but the reduction was comparable at the second and third year of treatment ( $p=0.719$ ) (Fig. 2). Since there was a greater $\mathrm{HBsAg}$ reduction during the first year of entecavir treatment, and the HBsAg level remained relatively stable thereafter, factors associated with $\mathrm{HBsAg}$ reduction were expected to differ according to pre- and post-first year treatment (Table 4).

Out of total patients 102 patients had HBsAg levels measurement during 1 year of treatment and 12 of 102 patients (11.8\%) showed significant HBsAg decline. In univariate analysis, baseline serum HBV DNA, HBsAg level and albumin were associated with $\mathrm{HBsAg}$ reduction. In multivariate analysis, baseline HBsAg level was the only independent predictor of HBsAg reduction, $\mathrm{p}<0.001$.

During the follow-up period, 12 of 74 patients (16.2\%) who were consistently tested for HBsAg level showed significant reduction after 1 year of treatment. Univariate analysis revealed that positive HBcAg expression and prolonged INR were associated with reduction. However, in multivariate analysis, positive $\mathrm{HBcAg}$ expression remained as the only independent factor. The cumulative incidence of significant HBsAg reduction was significantly greater in patients with positive $\mathrm{HBcAg}$ expression throughout the follow-up period ( $p=0.048$ ) (Fig. 1C).

\section{DISCUSSION}

Similar to previous studies, we showed that clinical and histological features of patients at baseline differed according to the clinical course of $\mathrm{CHB} .{ }^{8,13,14,21-23}$ Various patterns of $\mathrm{HBCAg}$ expression (nuclear, mixed, and cytoplasmic) in hepatocytes were dominant in HBeAg-positive patients, with eventual loss 
Table 4. Factors Associated with HBsAg Reduction during and after the First Year of Treatment

\begin{tabular}{|c|c|c|c|c|c|c|}
\hline \multirow{3}{*}{ Variable } & \multicolumn{6}{|c|}{ HBsAg reduction $\left(>0.5 \log _{10} \mathrm{IU} / \mathrm{mL}\right)$} \\
\hline & \multicolumn{3}{|c|}{ During 1st year $(\mathrm{n}=12 / 102)$} & \multicolumn{3}{|c|}{ After 1st year $(\mathrm{n}=12 / 74)$} \\
\hline & OR $(95 \%$ CI) & p-value* & p-value ${ }^{\dagger}$ & HR (95\% CI) & p-value* & p-value ${ }^{\dagger}$ \\
\hline Age, yr & 1.039 (0.982-1.099) & 0.193 & & $0.979(0.927-1.034)$ & 0.442 & \\
\hline Sex, male/female & $1.423(0.428-4.724)$ & 0.565 & & $3.081(0.675-14.067)$ & 0.143 & \\
\hline Liver cirrhosis, yes/no & $0.574(0.126-2.62)$ & 0.474 & & $1.38(0.415-4.586)$ & 0.599 & \\
\hline HBeAg, +/- & $1.101(0.331-3.656)$ & 0.875 & & 2.524 (0.682-9.336) & 0.165 & \\
\hline HBV DNA, $\log _{10} \mathrm{IU} / \mathrm{mL}$ & $1.615(0.945-2.76)$ & 0.08 & 0.669 & $1.995(1.034-3.85)$ & 0.39 & \\
\hline HBsAg, $\log _{10} I U / m L$ & $6.129(1.932-19.445)$ & 0.002 & $<0.001$ & $1.591(0.491-5.155)$ & 0.439 & \\
\hline $\mathrm{ALT}, \geq 200 /<200 \mathrm{IU} / \mathrm{L}$ & $1.191(0.359-3.956)$ & 0.775 & & $1.739(0.517-5.847)$ & 0.371 & \\
\hline Albumin, g/dL & $0.521(0.279-0.971)$ & 0.04 & 0.08 & $1.191(0.34-4.171)$ & 0.785 & \\
\hline PT, INR & $0.888(0.00-202.649)$ & 0.966 & & $233.103(2.197-22660.6)$ & 0.022 & 0.065 \\
\hline Bilirubin, $\mathrm{g} / \mathrm{dL}$ & $0.974(0.763-1.244)$ & 0.832 & & $1.027(0.862-1.224)$ & 0.764 & \\
\hline Platelet count, $\times 10^{3} / \mu \mathrm{L}$ & $0.994(0.983-1.006)$ & 0.336 & & $0.998(0.998-1.008)$ & 0.676 & \\
\hline HAI score, $\geq 9 /<9$ & $1.092(0.347-3.441)$ & 0.88 & & $0.891(0.282-2.818)$ & 0.845 & \\
\hline Fibrosis stage, $\geq 4 /<4$ & $0.375(0.101-1.385)$ & 0.141 & & $1.645(0.484-5.479)$ & 0.416 & \\
\hline HBcAg expression patterns & & 0.226 & & & 0.043 & 0.048 \\
\hline Absent $(<10 \%)$ & - & - & & - & - & - \\
\hline Cytoplasm ( $\geq 10 \%)$ & $1.856(0.34-10.133)$ & 0.475 & & $1.676(0.418-6.715)$ & 0.466 & 0.208 \\
\hline Nuclear \& mixed $(\geq 10 \%)$ & $3.041(0.858-10.777)$ & 0.085 & & $5.662(1.411-22.718)$ & 0.014 & 0.039 \\
\hline \multicolumn{7}{|l|}{ HBsAg expression patterns } \\
\hline \multicolumn{7}{|l|}{ Membranous expression } \\
\hline Absent vs present & $0.507(0.153-1.684)$ & 0.267 & & $1.157(0.345-3.874)$ & 0.813 & \\
\hline \multicolumn{7}{|l|}{ Intracytoplasmic expression } \\
\hline Diffuse vs nondiffuse & $0.895(0.289-2.775)$ & 0.847 & & $0.676(0.214-2.133)$ & 0.504 & \\
\hline $\begin{array}{l}\text { Non-submembranous } \\
\text { vs submembranous }\end{array}$ & $0.566(0.124-2.585)$ & 0.463 & & $0.348(0.045-2.695)$ & 0.312 & \\
\hline
\end{tabular}

Associations of HBsAg reduction during first year treatment were analyzed using binary logistic regression, and associations after first year treatment were assessed using Cox regression analysis.

HBsAg, hepatitis B surface antigen; OR, odds ratio; CI, confidence interval; HR, hazard ratio; HBeAg, hepatitis B e antigen; HBV, hepatitis B virus; ALT, alanine aminotransferase; PT, prothrombin time; INR, international normalized ratio; HAI, histologic activity index; HBcAg, hepatitis B core antigen.

*Univariate p-values; ${ }^{\dagger}$ Multivariate p-values were obtained after including the variables of the univariate analysis with p-values $<0.1$.

of HBcAg following HBeAg seroclearance. The main pattern of intracytoplasmic HBsAg expression also changed, from diffuse to globular or submembranous type, along with HBeAg seroclearance, and the incidence of membranous staining decreased. Considering the remarkable reduction in viral load in HBeAgnegative patients, these histologic changes might be used as a marker representing the enhanced host immune response against HBV.

Other studies generally evaluated disease activity according to membranous and nonmembranous expression of HBsAg. ${ }^{10,11}$ In contrast, the present study further evaluated intracytoplasmic (diffuse, globular, submembranous) HBsAg expression in combination with $\mathrm{HBcAg}$, and interestingly found that intracytoplasmic hepatocyte HBsAg expression patterns had greater clinical significance in disease progression than the presence of membranous expression in both HBeAg-positive and -negative patients. Based on these results, we expected good delineation of the evolution of $\mathrm{CHB}$ in $\mathrm{HBeAg}$-positive patients by the $\mathrm{HBcAg}$ and HBsAg expression pattern. At the initial phase, the hepatocyte $\mathrm{HBcAg}$ expression shifts from nucleus to cytoplasm with advancing age and intensifying hepatic inflammation and fibrosis, as suggested in the present as well as a previous study. ${ }^{9}$ Then, HBcAg expression ultimately disappears in association with a significant reduction of viral load, followed by the alteration of HBsAg expression pattern from non-submembranous (diffuse and globular) to submembranous type, in conjunction with a further increase in age and disease progression. This is the first study revealing that disease status in $\mathrm{HBeAg}$-positive CHB patients could be elegantly represented by proper integration of the hepatocyte $\mathrm{HBcAg}$ and HBsAg expression pattern. 
Furthermore, studies until now revealed that HBeAg-negative patients with hepatocyte $\mathrm{HBcAg}$ expression had higher serum HBV DNA and ALT levels, with more severe necroinflammation. ${ }^{24}$ However, the clinical significance of this was not seen in the present study, probably due to the low incidence and low degree of hepatocyte $\mathrm{HBcAg}$ expression in $\mathrm{HBeAg}$-negative patients. Instead, the intracytoplasmic HBsAg expression pattern had a significant clinical implication; submembranous intracytoplasmic HBsAg expression was associated with decreased viremia and lowered ALT levels, which is consistent with a study by Hsu et al.; ${ }^{10}$ that study indicated that submembranous expression reflects the late phase of inactive virus replication or integration.

Since the hepatocyte $\mathrm{HBcAg}$ or HBsAg expression was believed to appropriately reflect the status of disease activity and immune response, we analyzed the importance of these parameters for the prediction of antiviral treatment response. A few studies have shown the possible relationship between the expression of hepatocyte $\mathrm{HBcAg}$ and the response to antiviral treatment. ${ }^{12,13}$ However, no studies have been conducted to investigate the correlation between the intracytoplasmic hepatocyte HBsAg expression pattern and antiviral treatment response. To our knowledge, the present study is the first to assess the potential of hepatocyte HBsAg expression as a prognostic factor for antiviral treatment response in addition to the hepatocyte HBcAg.

The strength of this study compared to others is that we evaluated factors associated with treatment response using multivariate analysis for each treatment response. In HBeAgpositive patients, the histologic $\mathrm{HBsAg}$ and $\mathrm{HBcAg}$ expression predicted those who would achieve early VR, among those with unfavorable predictors. Furthermore, as compared with wellestablished conventional predictors of HBeAg seroclearance, such as low serum HBV DNA and high ALT levels, ${ }^{25}$ high HAI (score $\geq 9$ ) and negative $\mathrm{HBcAg}$ expression had greater significance in predicting HBeAg seroclearance. Therefore, when the usual predictors are not identified in patients who require antiviral treatment, histologic findings including $\mathrm{HBcAg}$ expression appears to be very useful in predicting treatment response, especially in patients with either low or fluctuating ALT levels due to concomitant liver injury secondary to other causes. On the other hand, no histological correlation with VR was found in HBeAg-negative patients, similar to a previous study. ${ }^{14}$ In fact, prediction of VR seems to be unnecessary in situation where HBeAg-negative patients are treated with high potent antiviral drug such as entecavir.

Previous studies ${ }^{26,27}$ reported that HBsAg declined rapidly within the first year of antiviral treatment, compared to the second and third years. The present study also demonstrated a significant drop in HBsAg level during the first year of treatment, while no prominent decrease was observed after 1 year; we therefore expected different factors to be associated with
HBsAg decline according to first year treatment and thereafter. Increased baseline serum HBsAg level was associated with significant HBsAg decline during the first year of treatment, while the presence of hepatocyte $\mathrm{HBcAg}$ expression was associated with later decline. HBsAg decline during the first year is mainly attributed to the reduction in number of virions in the serum, but when viral replication is completely suppressed following antiviral treatment, further HBsAg reduction depends on viral elimination from hepatocytes by host factors.

Circulating HBsAg is the product of covalently closed circular DNA (cccDNA) which is secreted in the form of HBV DNA-containing virion envelopes or empty HBsAg subviral particles. ${ }^{28}$ When antiviral treatment is used, the significant HBsAg decline during the first year relies on HBV DNA-containing virions; further HBsAg decline depends on the decrease in the number of hepatocytes harboring cccDNA, as well as enhanced host immunity with a direct effect on cccDNA. For the first time, this study revealed that the presence of hepatocyte $\mathrm{HBcAg}$ expression is a predictor of significant HBsAg reduction after HBV DNA is sufficiently suppressed. Ironically, the hepatocyte expression pattern of HBsAg was not able to predict HBsAg reduction, probably because $\mathrm{HBcAg}$ rather than $\mathrm{HBsAg}$ is highly immunogenic, and induces an important lymphocyte effector function. $\mathrm{HBcAg}$ is a major target of $\mathrm{HBcAg}$ specific cytotoxic T lymphocytes, ${ }^{29}$ and these lymphocytes mediate clearance of cccDNA through direct hepatocyte lysis.

In conclusion, we clarified the association between histologic findings of hepatocyte HBcAg and HBsAg expression and the disease status of chronic hepatitis $\mathrm{B}$, based on a large number of patients. Furthermore, we found that the degree of hepatocyte $\mathrm{HBcAg}$ expression is an important prognostic factor for antiviral treatment response in addition to the already known factors, such as low serum HBV DNA, high ALT levels, and high HAI score. Although the expression pattern of HBsAg significantly differed according to disease status, it has a lower clinical significance in predicting antiviral treatment response, compared to hepatocyte HBcAg expression.

\section{CONFLICTS OF INTEREST}

No potential conflict of interest relevant to this article was reported.

\section{ACKNOWLEDGEMENTS}

This study was supported by a grant from the Korea Healthcare Technology R\&D Project, Ministry of Health and Welfare, Republic of Korea (HI10C2020).

\section{REFERENCES}

1. Song IH, Kim KS. Current status of liver diseases in Korea: hepato- 
cellular carcinoma. Korean J Hepatol 2009;15 Suppl 6:S50-S59.

2. European Association for the Study of the Liver. EASL clinical practice guidelines: management of chronic hepatitis B virus infection. J Hepatol 2012;57:167-185.

3. Brunetto MR, Moriconi F, Bonino F, et al. Hepatitis B virus surface antigen levels: a guide to sustained response to peginterferon alfa-2a in HBeAg-negative chronic hepatitis B. Hepatology 2009;49:1141-1150.

4. Moucari R, Mackiewicz V, Lada O, et al. Early serum HBsAg drop: a strong predictor of sustained virological response to pegylated interferon alfa-2a in HBeAg-negative patients. Hepatology 2009;49:1151-1157.

5. Moucari R, Martinot-Peignoux M, Mackiewicz V, et al. Influence of genotype on hepatitis B surface antigen kinetics in hepatitis $\mathrm{B}$ e antigen-negative patients treated with pegylated interferonalpha2a. Antivir Ther 2009;14:1183-1188.

6. Hadziyannis SJ, Lieberman HM, Karvountzis GG, Shafritz DA. Analysis of liver disease, nuclear $\mathrm{HBcAg}$, viral replication, and hepatitis B virus DNA in liver and serum of HBeAg vs. anti-HBe positive carriers of hepatitis B virus. Hepatology 1983;3:656-662.

7. Hsu HC, Su IJ, Lai MY, et al. Biologic and prognostic significance of hepatocyte hepatitis B core antigen expressions in the natural course of chronic hepatitis B virus infection. J Hepatol 1987;5:45-50.

8. Kim TH, Cho EY, Oh HJ, et al. The degrees of hepatocyte cytoplasmic expression of hepatitis B core antigen correlate with histologic activity of liver disease in the young patients with chronic hepatitis B infection. J Korean Med Sci 2006;21:279-283.

9. Son MS, Yoo JH, Kwon CI, et al. Associations of expressions of $\mathrm{HBcAg}$ and HBsAg with the histologic activity of liver disease and viral replication. Gut Liver 2008;2:166-173.

10. Hsu HC, Lai MY, Su IJ, et al. Correlation of hepatocyte HBsAg expression with virus replication and liver pathology. Hepatology 1988;8:749-754.

11. Chu CM, Liaw YF. Membrane staining for hepatitis B surface antigen on hepatocytes: a sensitive and specific marker of active viral replication in hepatitis B. J Clin Pathol 1995;48:470-473.

12. Uzun Y, Bozkaya H, Erden E, et al. Hepatitis B core antigen expression pattern reflects the response to anti-viral treatment. J Gastroenterol Hepatol 2006;21:977-981.

13. Shi KD, Hwang SG, Choi JH, et al. Hepatitis B core antigen expression pattern predicts response to lamivudine therapy in patients with chronic hepatitis B. Korean J Hepatol 2008;14:197-205.

14. Lee JG, Hwang SG, Yoon H, et al. Hepatitis B core antigen expression in hepatocytes reflects viral response to entecavir in chronic hepatitis B patients. Gut Liver 2013;7:462-468.

15. Cho JH, Yoon KH, Lee KE, et al. Distribution of hepatitis B virus genotypes in Korea. Korean J Hepatol 2009;15:140-147.

16. Song BC, Cui XJ, Kim H. Hepatitis B virus genotypes in Korea: an endemic area of hepatitis B virus infection. Intervirology 2005;48:133-137.

17. Kim H, Jee YM, Song BC, et al. Molecular epidemiology of hepatitis $B$ virus (HBV) genotypes and serotypes in patients with chronic HBV infection in Korea. Intervirology 2007;50:52-57.

18. Seto WK, Wong DK, Fung J, et al. A large case-control study on the predictability of hepatitis B surface antigen levels three years before hepatitis B surface antigen seroclearance. Hepatology 2012;56:812-819.

19. Chu CM, Yeh CT, Chien RN, Sheen IS, Liaw YF. The degrees of hepatocyte nuclear but not cytoplasmic expression of hepatitis B core antigen reflect the level of viral replication in chronic hepatitis B virus infection. J Clin Microbiol 1997;35:102-105.

20. Ishak K, Baptista A, Bianchi L, et al. Histological grading and staging of chronic hepatitis. J Hepatol 1995;22:696-699.

21. Gudat F, Bianchi L, Sonnabend W, Thiel G, Aenishaenslin W, Stalder GA. Pattern of core and surface expression in liver tissue reflects state of specific immune response in hepatitis B. Lab Invest 1975;32:1-9.

22. Ray MB, Desmet VJ, Bradburne AF, Desmyter J, Fevery J, De Groote J. Differential distribution of hepatitis B surface antigen and hepatitis B core antigen in the liver of hepatitis B patients. Gastroenterology 1976;71:462-469.

23. Ray MB, Desmet VJ, Fevery J, De Groote J, Bradburne AF, Desmyter J. Distribution patterns of hepatitis B surface antigen (HBsAg) in the liver of hepatitis patients. J Clin Pathol 1976;29:94-100.

24. Huang YH, Hung HH, Chan CC, et al. Core antigen expression is associated with hepatic necroinflammation in e antigen-negative chronic hepatitis B patients with low DNA loads. Clin Vaccine Immunol 2010;17:1048-1053.

25. Perrillo RP, Lai CL, Liaw YF, et al. Predictors of HBeAg loss after lamivudine treatment for chronic hepatitis B. Hepatology 2002;36:186-194.

26. Seto WK, Liu K, Wong DK, et al. Patterns of hepatitis B surface antigen decline and HBV DNA suppression in Asian treatmentexperienced chronic hepatitis B patients after three years of tenofovir treatment. J Hepatol 2013;59:709-716.

27. Zoulim F, Carosi G, Greenbloom S, et al. Quantification of HBsAg in nucleos $(t)$ ide-naïve patients treated for chronic hepatitis B with entecavir with or without tenofovir in the BE-LOW study. J Hepatol 2015;62:56-63.

28. Chan HL, Thompson A, Martinot-Peignoux M, et al. Hepatitis B surface antigen quantification: why and how to use it in 2011: a core group report. J Hepatol 2011;55:1121-1131.

29. Mondelli MU, Bortolotti F, Pontisso P, et al. Definition of hepatitis $B$ virus (HBV)-specific target antigens recognized by cytotoxic $T$ cells in acute HBV infection. Clin Exp Immunol 1987;68:242-250. 